\title{
PEDAGOŠKO-ANDRAGOŠKI DNEVI 2020
}

Pedagoško-andragoški dnevi (PAD) se na Oddelku za pedagogiko in andragogiko Filozofske fakultete Univerze v Ljubljani organizirajo že skoraj štiri desetletja in so tradicionalno vsakoletno strokovno posvetovanje slovenskih pedagogov in andragogov.

Idejo o vsakoletnem strokovnem oddelčnem srečanju visokošolskih učiteljev in diplomantov je začela uresničevati v začetku osemdesetih let 20. stoletja prof. dr. Ana Krajnc po zgledu dopolnilnega in nadaljnjega izobraževanja na kanadskih univerzah (Continuing Education Assessment in Canadian Universities) in na Univerzi Cambridge. Dopolnilno in nadaljnje izobraževanje se je na oddelku poimenovalo Pedagoško-andragoški dnevi (PAD), saj je bil njihov temeljni namen, da so se diplomanti in diplomantke srečevali in izpopolnjevali znanje, s tem pa je prihajalo do implementacije teoretičnih in praktičnih znanj ter do kakovostnega nadaljnjega izobraževanja (continuing education).

Ugotavljamo, da so PAD potekali različno dolgo, sprva od dva do tri dni, kasneje en dan. Sprva so bili vanj aktivno vključeni večinoma visokošolski učitelji in diplomanti Oddelka za pedagogiko in andragogiko, občasno pa so na PAD sodelovali tudi gostujoči predavatelji z različnimi aktualnimi temami. Cilj je bil v druženju in razpravljanju raziskovalcev in praktikov. S predstavitvijo svojih raziskav so sodelovali tudi novi doktorji znanosti našega oddelka.

PAD so se skozi čas vse bolj usmerjali v določene izbrane teme, ki so bile takrat aktualne oziroma so bile rezultat potreb diplomantov v praksi. PAD so vedno dajali možnost nadaljnjega izmenjevanja strokovnih znanj in izkušenj ter druženja. Vse to je pomembno vplivalo na razvoj obeh znanstvenih disciplin, pedagogike in andragogike. PAD so učinkovita oblika strokovnega srečanja, kjer se pedagogi in andragogi seznanjajo z novimi spoznanji iz stroke, novimi rezultati iz raziskovanj, tako da pride do implementacije novosti, dilem, problemov v praksi ter ustvarjanja možnosti za kakovostno strokovno reševanje teh vprašanj.

$\mathrm{Na}$ Oddelku za pedagogiko in andragogiko so organizacijski odbor PAD 2020 sestavljali: dr. Monika Govekar-Okoliš - predsednica ter člani dr. Katja Jeznik, asist. Nina Breznikar in dr. Marko Radovan. Program PAD 2020 je zajemal plenarna predavanja, dve vzporedni skupini, v katerih so potekale predstavitve primerov dobrih praks, in Doktorsko kavarno.

PAD so letos potekali 23. januarja na Filozofski fakulteti Univerze v Ljubljani (38. izvedba). Naslovna tema srečanja je bila Vplivi sodobnih tehnologij na učenje in izobraževanje. To vprašanje je izjemnega pomena za današnji čas. Vse bolj ugotavljamo, da nas sodobna tehnologija spremlja že na vsakem koraku, v zasebnem, javnem in poklicnem življenju, 
vse bolj postajamo odvisni od nje, saj prinaša nove načine našega dela, življenja in tudi učenja ter izobraževanja. Omenimo rezultate raziskave mednarodne Organizacije za gospodarsko sodelovanje in razvoj (OECD - Organisation for Economic Co-operation and Development), v kateri so sodelovali tudi strokovnjaki Inštituta Jožef Stefan iz Ljubljane. Raziskovali so vpliv digitalizacije na sodobno družbo ter izsledke objavili v znanstveni monografiji, ki je izšla junija 2019 z naslovom Umetna inteligenca v družbi (Artificial Intelligence in Society). Ugotovitve raziskave odpirajo širok pogled na področje umetne inteligence iz več dimenzij (tehnične, gospodarske in aplikativne), analiziran pa je tudi njen vpliv na družbo. Raziskava postavlja tudi nova vprašanja in izzive, povezane s človekovimi vrednotami, zasebnostjo, varnostjo, odgovornostjo v sodobni družbi. Ti izzivi in zavedanje, da se procesom uveljavljanja sodobnih in vse bolj sofisticiranih tehnologij ne moremo izogniti, med drugim terja tudi resne strokovne razmisleke pedagogov in andragogov o tem, kakšni so vplivi teh tehnologij na procese učenja in izobraževanja. Zato je bil glavni namen srečanja PAD spoznati, kako sodobna tehnologija spreminja podobo učenja in izobraževanja ter kakšni so in bodo kratkoročni in dolgoročni učinki tehnoloških vplivov na vlogo vzgojno-izobraževalnih institucij formalnega in neformalnega izobraževanja otrok, mladine, odraslih in starejših v Sloveniji.

Ob odprtju PAD sta dekan Filozofske fakultete dr. Roman Kuhar in predstojnica Oddelka za pedagogiko in andragogiko dr. Nives Ličen v uvodnem nagovoru poudarila pomen PAD in njihove tematike za aktualni razvoj učenja in izobraževanja v Sloveniji. O formalnostih poteka PAD je spregovorila dr. Monika Govekar-Okoliš, ki je bila moderatorka plenarnega dela predavanj. O tem, kako pomembna je sodobna tehnologija za učenje in izobraževanje vsakega posameznika, so predavatelji na PAD predavali z različnih strokovnih vidikov, tako pedagoških kot andragoških, in pri tem prikazali zanimive rezultate raziskav, poudarili nove poglede in poskušali odgovoriti na naslednja vprašanja:

- Ali naložba v informacijsko-komunikacijsko tehnologijo (IKT) pomeni tudi že naložbo $v$ znanje? Dr. Marko Radovan je v svojem prispevku omenil, da se ne dogaja prvič, da izobraževalna tehnologija »zahteva« umik učitelja iz učilnice. Vendar je poudaril, da se to, tako kot prej, tudi danes ne bo zgodilo. Takšen sklep je dokazoval z rezultati raziskav. Ugotovitve kažejo, da informacijsko-komunikacijska tehnologija (IKT) prispeva $\mathrm{k}$ večji nazornosti pouka, povečuje dostop do informacij, olajšuje individualizacijo v izobraževanju in posledica njene rabe je seveda digitalna pismenost. Potenciali in obljube so veliki, a raziskave tudi kažejo, da pozitiven vpliv uvajanja sodobne tehnologije na različne izobraževalne ravni ni samoumeven. Raba IKT ne vodi v zvišanje šolskih ocen, čista »on-line « izvedba izobraževanja ima tudi slabe učinke na dosežke. Zaradi njene rabe prihaja do povečevanja neenakosti med učenci glede na izobrazbo staršev. Raziskava PISA je denimo pokazala, da več rabe računalnika $v$ šoli pomeni nižje dosežke. Uporaba tehnologije torej ni nujno povezana $\mathrm{z}$ večjo učno uspešnostjo, temveč jo lahko ob neustreznem vključevanju v pouk celo poslabša. Po drugi strani daje njena raba boljše rezultate tam, kjer omogoča učenje s posamezniku prilagojenim tempom, zelo je uporabna za simulacije in delo zunaj učilnice. Uporabi IKT se torej ne gre odreči, je pa zelo pomemben način njene uporabe. Učitelj mora vedeti, kaj želimo 
pri pouku in izobraževanju doseči, in če ugotovimo, da nam lahko pri tem pomaga tehnologija, potem je njena raba smiselna, sicer ne. Predavatelj je poudaril tudi, da naložbe v IKT na področju procesov učenja in izobraževanja spremljajo zelo visoki stroški, pri čemer stroški opreme in amortizacije niti niso najvišji. Do smiselne rabe tehnologije namreč pridemo le, če so učitelji za njeno tehnično in didaktično rabo res dobro usposobljeni. Zato sta potrebna celovito in kontinuirano usposabljanje učiteljev ter priprava ustreznih gradiv, kar pa sta najvišji strošek, na katerega odločevalci prepogosto pozabijo. Sklepna misel predavatelja je bila, da so naložbe v IKT smiselne le, če nam tehnologija omogoča doseganje tistega, česar brez podpore IKT ne bi zmogli.

- Ali lahko stroj zavzame mesto učitelja? S tem provokativnim vprašanjem je začel svoje predavanje dr. Damijan Štefanc. Tudi on je povedal, da imajo razprave, povezane $\mathrm{z}$ vlogo tehnologije v izobraževanju, že dolgo zgodovino. Ob eksponentnem razvoju računalniško podprte tehnologije pa je to vprašanje danes še posebej aktualno, še zlasti zato, ker je človekov odnos do tehnologije zelo ambivalenten: stroj je ustvaril človek, z njim živi in se ga hkrati boji. Odgovor na vprašanje, ali stroj lahko zavzame mesto učitelja, je po eni strani odvisen od našega razumevanja, kaj je stroj, po drugi strani pa od našega razumevanja vloge učitelja. V času, ko človek deluje s pomočjo strojnih komponent (na primer srčni spodbujevalnik) in ko človekov prijatelj postaja robot, meja med človekom kot organskim in humanim bitjem ter strojem ni več tako enoznačna. Učitelja v vlogi posredovalca informacij stroj zlahka zamenja, precej težje pa ga zamenja v vlogi posredovalca znanja in vzgojitelja. Učenec za usvajanje znanja in svoje formiranje potrebuje pedagoško vez, za katero smo vselej predpostavljali, da je to humana vez, ki je mogoča zgolj med učencem in učiteljem, da učitelju omogoča pedagoško vodenje, usmerjanje in značajsko oblikovanje učenca. Pa se lahko vez splete tudi med človekom in strojem? Odgovor na to vprašanje še zdaleč ni tako samoumeven, kot bi pričakovali, ugotavlja predavatelj.

- Kakšne so bralne navade študentk in študentov, ki se izobražujejo za pedagoške poklice: kje smo in kam gremo? Predavatelji dr. Mojca Kovač Šebart, dr. Miha Kovač in dr. Jasna Mažgon so predstavili prve izsledke empirične raziskave, opravljene v letu 2019. Njen glavni namen je bil spoznati bralne navade študentov študijskih programov Filozofske in Pedagoške fakultete Univerze v Ljubljani, v katerih se izobražujejo bodoči učiteljice in učitelji. Ugotovitve raziskave kažejo, da študentska populacija, ki je bila vključena v raziskavo, v primerjavi s splošnim prebivalstvom v Sloveniji v povprečju prebere več knjig, vendar je število knjig, ki jih preberejo študentje, še vedno razmeroma majhno. Študentje najpogosteje berejo priročnike in lahkotnejša besedila o osebni rasti. Bistveno redkeje posegajo po zahtevnejših besedilih. Rezultati raziskave odpirajo številna vprašanja, vezana tako na širše družbene kot tudi ožje izobraževalne cilje. Zdi se, da je branje knjig le še deklarativna vrednota, če sploh, saj branje knjig, pa tudi znanje in širša kulturna omika v sodobni družbi izgubljajo pomen. Ali od učencev sploh še zares pričakujemo, da bodo brali, zlasti da bodo brali zahtevnejše leposlovje, esejistiko in podobno? Kam družbo, učitelje in mlade generacije usmerjajo mednarodna preverjanja funkcionalne pismenosti? Na tovrstna vprašanja bomo 
v prihodnje morali poiskati odgovore, so opozorili predavatelji in poudarili, da bodo bralne navade prihodnjih generacij odvisne predvsem od tega, kakšne cilje vzgoje in formiranja subjekta si bomo zastavili.

- Kam se lahko skrijemo v digitalnem panoptiku? Antropolog dr. Dan Podjed je v svojem predavanju najprej opisal oblikovanje koncepta digitalnega panoptika. Oprl se je na idejo Jeremyja Benthama, filozofa in pravnika iz 18. stoletja, ki si je zamislil svojevrstno stavbo, poimenovano panoptikum. Namenjena je bila nadzorovanju zapornikov, duševnih bolnikov in drugih ljudi, ki jih je smiselno imeti vseskozi na očeh, da izboljšajo svoje navade in ne skrenejo na napačno pot. Benthamova ideja se takrat ni udejanjila, je pa po predavateljevih besedah na nepričakovan način zaživela v 21 . stoletju. Namesto stražnika nas na prostem snemajo kamere, merijo radarji, Alexa, Siri, Cortana in druge digitalne asistentke nas poslušajo v zasebnosti doma, $\mathrm{v}$ torbicah prostovoljno nosimo »prisluškovalne in sledilne naprave« (pametne telefone), $\mathrm{s}$ katerimi mobilnim operaterjem in drugim podjetjem nenehno sporočamo, kje smo in kaj počnemo. Benthamove »panoptične sanje « se danes uresničujejo, saj živimo v gigantskem panoptikumu, ki nas ves čas nadzira in zbira podatke o nas. Kakšni so izzivi pedagogike in andragogike ter nasploh izobraževanja in učenja v času, ko imamo več medosebnih stikov prek naprav kot neposredno iz oči v oči? Predavatelj je prikazal tri scenarije za prihodnost digitalnih družb: digitalni totalitarizem, digitalni kapitalizem in digitalno demokracijo. Zavzel se je za aktivno prizadevanje za uveljavljanje digitalne demokracije, ki med drugim vključuje državljanske pobude za ohranjanje zasebnosti, širjenje znanja o digitalni družbi v vzgojno-izobraževalnem sistemu, krepitev kakovosti odnosov v zasebnem življenju in skupnosti ter spodbujanje posameznikov $\mathrm{k}$ vzdrževanju lastnih otočkov zasebnosti.

- Kakšna je ustvarjalna raba multimedije v vzgoji z umetnostjo? Dr. Robi Kroflič je v svojem predavanju poudaril, da človeška družba multimedijo dojema kot pharmakon - zdravilo in strup hkrati. Multimedijo odlikuje velika sugestivna moč, ki je pogosto zlorabljena za namene propagande in zasvajanja, hkrati pa jo lahko umestimo v funkciji subjektifikacije in rekonstrukcije političnega prostora. Odpira se prostor za boj zoper lingvistični kapitalizem, ki ne le homogenizira naravne jezike, ampak obljublja tudi računalniško generirane zgodbe, je opozoril predavatelj. Dvojna in kontroverzna je vloga digitalne tehnologije tudi pri vzgoji in izobraževanju: na eni strani ponuja številna sredstva za izražanje lastnih idej, občutkov, identitetnih predstav, možnosti vstopanja v širšo družbeno realnost, na drugi strani pa vodi v omejevanje učenja. Usvajanje znanja ni usvajanje informacij, ampak ustvarjanje pomena. Strojno (globoko) učenje ni učenje z razumevanjem, ampak polnjenje algoritmov s primeri. Strojno učenje je kot sledenje potem, ki so vse vnaprej predvidene - bomo pri učenju le še kot vozniki, ki izbiramo med ponujenimi potmi?

Po plenarnih predavanjih se je program nadaljeval s predstavitvami primerov dobrih praks uvajanja sodobnih IKT v učenje in izobraževanje, in sicer v dveh vzporednih skupinah. Skupino primerov dobrih praks z andragoškega področja je moderiral dr. Marko Radovan. Prvi primer dobre prakse z naslovom Prostovoljsko učenje računalništva v dvojicah Znaš, 
nauči drugega je predstavila dr. Ana Krajnc. Opisala je, kako so na Slovenski univerzi za tretje življenjsko obdobje v Ljubljani kot odziv na splošne potrebe starejših ljudi po znanju razvili prostovoljsko učenje računalništva za starejše. Na primerih je prikazala, kako je v današnjem času najpomembnejše znanje. Imenovala ga je tudi »darilo«, saj učinkuje na sočloveka, ga bogati, hkrati pa postavlja temelje za učečo se družbo. Iz predstavljenega primera smo se naučili, kako starejši odrasli pridobivajo računalniško pismenost, kako je pomembno prostovoljsko učenje $\mathrm{v}$ dvojicah in kakšne nove neformalne oblike (na primer patronažno izobraževanje) kroženja znanja se postopoma uveljavljajo.

V primeru dobre prakse z naslovom Uvajanja kombiniranega učenja na UPI - Ljudski univerzi Žalec smo spoznali, kako so na omenjeni instituciji posodobili učno metodologijo in s tem izobraževalne programe naredili privlačnejše in dostopnejše za udeležence. Tina Baloh in Tina Ojsteršek sta opisali pot svojega usposabljanja o kombiniranem učenju v Cambridgeu v okviru učne mobilnosti za posameznike programa Erasmus+. Po vrnitvi v Slovenijo sta začeli na UPI - Ljudski univerzi Žalec zaposlene in učitelje izobraževati na delavnicah, na katerih sta predstavili koncept kombiniranega učenja. Njuno delo je bilo zelo dobro sprejeto, saj so bili učitelji v izobraževanju odraslih navdušeni nad tem konceptom. Izdali sta tudi več priročnikov o kombiniranem učenju (slovenski izvod sta prinesli na vpogled) in izvedli več nadaljnjih usposabljanj. Cilj njunega dela je, da bi v prihodnje udeležencem ponudili izobraževalne programe, ki bi izkoriščali prednost uporabe IKT, s tem pa omogočali več fleksibilnosti učnega procesa in individualizacije.

Medgeneracijsko učenje, digitalna doba in posthumanizem je bil naslov predstavitve s področja akcijske raziskave interdisciplinarne skupine študentov in učiteljev (Manca Kozlovič, Mojca Suhovršnik, Urša Kapler, Nina Kranjac, Karin Petko, dr. Silva Bratož, dr. Matevž Pesek in dr. Nives Ličen) s Filozofske fakultete Univerze v Ljubljani in Dnevnega centra za starejše Koper. Prikazan in opisan je bil primer dobre prakse izobraževanja ter oblikovanja i-učbenika, ki nastaja v medgeneracijskem in interdisciplinarnem sodelovanju. Cilj je, da i-učbenik postane uporaben za različne generacije, ki se učijo angleškega jezika.

Drugo skupino primerov dobrih praks s pedagoškega področja je moderiral dr. Damijan Štefanc. Najprej je bil predstavljen primer prakse z naslovom Naslavljanje spletnega nasilja s pomočjo tehnike digitalnega pripovedništva - projekt Nasilne zveze so brez zveze (CSD Južna Primorska). Mag. Damjana Jurman in Tomaž Pavkovič sta prikazala, kako vladne in nevladne organizacije delujejo na področju preprečevanja nasilja v obalno-kraški regiji. Projekt že od leta 2016 ozavešča o različnih oblikah nasilja, stereotipih in predsodkih, povezanih s spolnimi vlogami, ter o nesprejemljivosti nasilja v medosebnih odnosih. Osrednja aktivnost, ki sta jo opisala avtorja, je bilo obravnavanje spletnega nasilja s pomočjo tehnike digitalnega pripovedništva, ki je oblika pripovedovanja osebnih zgodb s fotografijami, animacijami, zvokom, besedilom.

Primer dobre prakse $\mathrm{z}$ naslovom Tehnologije pri razvijanju večrazsežnostnih pismenosti: vzgoja za kritičnost in odgovornost je prikazal inovativen pedagoški proces v prvem vzgojno-izobraževalnem obdobju na OŠ bratov Polančičev Maribor. Avtorici dr. Vida 
Vončina Vodeb in Polona Legvart sta predstavili, kako se lahko inovativno odzovemo na izzive, ki jih v vzgojo in izobraževanje prinašajo nove tehnologije in mediji. V središče sta postavili učence, ki so s pomočjo tehnologije kreativno izdelovali različne izdelke. Pokazali sta, kako je mogoče za vzgojne in izobraževalne namene izkoristiti vsebine in tehnologije, ki jih otroci v šolo prinesejo iz digitalnega sveta, v katerem preživijo vedno več svojega prostega časa.

Zadnji primer dobre prakse je bil z Inštituta 4.0, šole robotike in programiranja za osnovnošolce in odrasle, kjer se izvajajo tečaji programiranja in robotike za vse generacije. Tilen Tomazin je predstavil primer dobre prakse z naslovom Bi pouk programiranja in drugih digitalnih znanj moral postati obvezen? Avtor je opisal dejavnosti Inštituta 4.0, šole robotike in programiranja, prek katerih udeleženci ob zanimivem pristopu pridobivajo znanja iz programiranja in robotike. Po mnenju avtorja so znanja programiranja in robotike ena izmed ključnih kompetenc, s katerimi moramo opremiti današnje generacije. Poudaril je, da bi na sistemski ravni morali opraviti konceptualni razmislek o tem, kako bi vsebine programiranja in robotike vključili v vzgojno-izobraževalno prakso, pri čemer bi bili tovrstnih vsebin deležni že vsi osnovnošolci.

PAD 2020 se je sklenil z Doktorsko kavarno, ki sta jo vodili dr. Andreja Hočevar in dr. Nives Ličen. Doktorska kavarna že nekaj let omogoča pomembno srečanje doktorskih študentov z Oddelka za pedagogiko in andragogiko, katerega cilj sta povezovanje in izmenjava znanj ter izkušenj.

$\mathrm{Na}$ koncu lahko ugotovimo, da ima sodobna digitalna tehnologija velik potencial za izboljšanje vzgojnih in didaktičnih praks $\mathrm{v}$ formalnem in neformalnem izobraževanju tako otrok, mladine, odraslih kot starejših. Vendar bo ta potencial uresničen le, če bodo izpolnjeni vsaj naslednji ključni pogoji:

- Naložbe v sodobno digitalno tehnologijo moramo razumeti širše, tudi kot naložbe v znanje učiteljev v formalnem in neformalnem izobraževanju. Uvajanje novih tehnologij brez vedenja, s kakšnim namenom jih bomo uporabili in kako bodo izboljšale doseganje ciljev, ki smo si jih zastavili, ne pomeni zgolj finančno izgubo, temveč celo niža kakovost učenja, poslabšuje učne dosežke ter zmanjšuje socialno pravičnost $\mathrm{v}$ izobraževanju. Del teh naložb mora torej biti namenjen tudi celoviti didaktični podpori učiteljem in pripravi raznolikih podpornih gradiv.

- Sodobna digitalna tehnologija ne nadomešča učitelja. Pedagoški/andragoški proces brez učitelja ne more biti uspešen ne v vzgojnem in ne v učnem smislu: samo učitelj lahko učencem oziroma odraslim udeležencem pomaga oblikovati pomene in smisel, brez pedagoške/andragoške vezi ni vzgojnega vplivanja, ni kreativnosti in ni motiviranosti.

- Uvajanje sodobne digitalne tehnologije mora biti tesno povezano z vzgojnimi in socializacijskimi cilji, ki jim sledimo. Zato so didaktični in širši pedagoški/andragoški razmisleki vedno na prvem mestu. Sodobno digitalno tehnologijo uporabljamo zlasti za doseganje tistega, česar brez njene podpore ne bi zmogli (prilagajanje tempa učenja posamezniku, simulacije, interaktivna nazornost in podobno). 
- Sodobna digitalna tehnologija je hkrati »zdravilo« in »strup«: učeče se lahko opolnomoči ali zasužnji. K opolnomočenju prispevajo kreativna raba tehnologije, ozaveščanje o njenih pasteh, poznavanje značilnosti življenja v digitalni družbi in tudi obvladovanje programskih jezikov. Posebna pozornost mora biti namenjena odpravljanju razlik v dostopnosti in ravni obvladovanja sodobne tehnologije glede na socialno ozadje učečih se posameznikov, ne glede na njihovo starost.

Sklenemo lahko, da je nujen nadaljnji razmislek o okrepitvi izobraževalnega in emancipatornega potenciala sodobne digitalne tehnologije $\mathrm{v}$ izobraževanju ter $\mathrm{s}$ tem povezan razmislek o okrepitvi znanja računalništva in znanja o življenju v digitalni družbi v programih izobraževanja na vseh stopnjah izobraževalnega sistema kot tudi zunaj njega, in sicer tako v smislu obsega kot tudi ciljev, saj funkcionalno učenje v Sloveniji ne zadošča več. Sodobni človek se mora nenehno izobraževati, da lahko preživi, saj se čas inovacij krajša, življenjska doba pa se daljša. Zato je pomembno vseživljenjsko učenje in izobraževanje vseh tudi na področju sodobne digitalne tehnologije.

Da je znanje uporabe sodobne digitalne tehnologije nujno za vse ljudi, občutimo predvsem v zadnjem obdobju, ko je koronavirus domala v vsem svetu kot tudi pri nas ohromil vse naše življenje in delo. Ob tem ni ostal imun niti sistem izobraževanja, ki se je tudi v Sloveniji iz neposrednega poučevanja v vzgojno-izobraževalnih institucijah preselil predvsem v poučevanje na daljavo. Na eni strani je spremenjen način dela velik izziv za pedagoške in andragoške delavce, ki se morajo hitro prilagoditi in se priučiti različnih načinov, ki omogočajo učenje in izobraževanje na daljavo. Hkrati pa so pred velikim izzivom tudi učenci/dijaki/študentje/udeleženci izobraževanja odraslih, ki za usvajanje vsebin na daljavo prav tako potrebujejo znanje o uporabi IKT - to še zdaleč, tudi pri mlajših generacijah, ni samoumevno. Prepričani smo, da nas bo ta izkušnja obogatila, hkrati pa naj nam bo tudi v opomin, da je vseživljenjsko učenje in izobraževanje na področju sodobne digitalne tehnologije med ključnimi.

Monika Govekar-Okoliš, Katja Jeznik, Nina Breznikar, Klara Skubic Ermenc 